\title{
ASSESSMENT OF KNOWLEDGE REGARDING PICA HABITS IN CHILDREN AMONG MOTHERS OF PRESCHOOL CHILDREN IN RURAL AREA OF JAMMU
}

\author{
Mrs. Jyoti Kapoor* | Dr. Chandra Prakash Sharma** \\ * Lecturer, Government Medical College, Bakshi Nagar, Jammu, India. \\ ** Ph. D. Guide, Himalayan University, Itanagar, Arunachal Pradesh, India. \\ DOI: http://doi.org/10.47211/trr.2019.v05i02.005 \\ Received $15^{\text {th }}$ November 2019, Accepted $5^{\text {th }}$ December 2019, Published $20^{\text {th }}$ December 2019 \\ "What is done to children, they will do to society" \\ - Karl A. Menninger
}

\begin{abstract}
Background: The child is the most precious possession of mankind, most loved and perfect in its innocence. Underfive children tend to develop eating habits during their first 2 to 3 years of life. During childhood, the eating preferences and attitudes related to food habits are formed by family influences and culture. Since the world is full of strange diseases and disorders, there is also one known as "pica." It is one of the strangest eating disorders of all. Pica is an eating disorder of childhood which is characterised by the persistent urge to eat inedible things such as clay, hair, wood, coal, plaster etc. Objective: To assess the knowledge regarding 'pica' habits in children among mothers of pre-school children in a rural area of Jammu. Methods: For the present study, Evaluative research approach and preexperimental research design were used. The research setting was the rural area of Jeevan Nagar in Jammu. The sample consisted of 30 mothers of pre-school children. Non probability convenient sampling technique was used to select the sample. Results: The results revealed that in pre-test, maximum number (56.6\%) had average knowledge followed by those 20\%, who had good knowledge, $13.3 \%$ and $10 \%$ who had very good and poor knowledge respectively; whereas in post-test, majority (100\%) of mothers had very good knowledge. The association of knowledge of mothers with selected socio-demographic variables was also significant.

Hence, it was concluded that planned teaching programme had a great effect on knowledge regarding 'pica habits' in children, among mothers of pre-school children. The major goal of imparting knowledge is to bring about changes in the behavioural habits of children.
\end{abstract}

Keywords: Pica, Pre-School, Knowledge

\section{About Authors:}

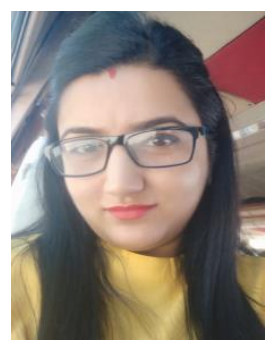

Mrs. Jyoti Kapoor did MSc (N) Obstetrics \& Gynaecology \& MSc (Health Care \& Hospital Administration). She is working as Lecturer in Government Medical College, Bakshi Nagar, Jammu, India. She has published papers in various National and International Journals. She is Ph.D. Scholar at Himalayan University, Itanagar, Arunachal Pradesh, India.

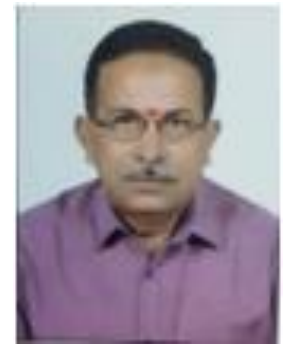

Dr. Chandra Prakash Sharma is Ph.D. Guide at Himalayan University, Itanagar, Arunachal Pradesh, India. He has published papers in various National and International Journals and organized various workshops and conferences. 


\section{INTRODUCTION}

The child is the most precious possession of mankind, most loved and perfect in its innocence. A child is beautiful, a source of joy and happiness, a focus of love and care and a subject of dream for the future.

Under-five children tend to form eating habits during the first 2 to 3 years of life. During childhood, the eating preferences and attitudes related to food habits are established by family influences and culture. Unhealthy diets are common among lower income families, often because of the lack of nutritious fresh fruits and vegetables and adequate milk in diet. In addition, the lifestyles of homeless and migrant children place these populations at risk for inadequate food causing nutrient deficiencies, developmental and growth delay, depression, hunger and behaviour problems. ${ }^{1}$

The world is full of strange diseases and disorders, but the one known as 'Pica' is one of the strangest eating disorders of all. Pica is an eating disorder, of childhood which is characterised by a persistent urge to eat inedible things such as clay, hair, wood, coal, plaster etc. It is associated with the passage of these substances unchanged in the stool, and with radiological evidence of their presence in the gut when they are radio-opaque. ${ }^{2}$

The term Pica comes from the Latin word meaning magpie, presumably named after this bird's peculiar eating behaviors. The magpie shows an indiscriminate preference for foods and nonfoods. Pica of dirt and clay was known to the Greeks and the Romans and was recorded in a 13th century Latin work. Pica was first addressed in a medical book in 1563, where Geophagia was described in pregnant women and in children. ${ }^{3}$

Pica is known to occur throughout the world. It is common enough that up to one quarter of children seen in mental health facilities, have some symptoms of this disease. Worldwide, $25 \%$ to $33 \%$ of all Pica cases involve small children, $20 \%$ are pregnant women, and $10 \%$ to $15 \%$ are individuals with learning disabilities. The true incidence of pica is not known but it is estimated to be $75 \%$ in infants, $15 \%$ in $2-3$ years old toddlers and $10-33 \%$ among the institutionalised mentally retarded children. ${ }^{4}$

A study was conducted on "Clinical profile of pica in childhood". The various aspects of clinical profile of 200 children with pica had been highlighted. There was a definite male predominance i.e. M: F=1.5:1 and majority of children belonged to 2-4 years age group. Direct history of pica was provided by $32 \%$ mothers. The presenting complaints were cough (30\%), pain in abdomen (34\%), poor appetite (26\%), increasing pallor (19\%), diarrhoea on and off (17\%), vomiting $(12 \%)$, abdominal fullness $(11 \%)$ generalised weakness $(8 \%)$, passing of worms in stool $(7 \%)$ etc. The pica was observed more in children of working mothers as compared to house wives. Pica was seen more in bottle-fed children as compared to breast-fed. Family history for pica was positive in $44 \%$ children. $46 \%$ children had poor nutritional status. Intestinal parasites were identified in $63 \%$ of pica children as compared to $18 \%$ in control. Initial hemoglobin levels were less than $8 \mathrm{gm} / \mathrm{dl}$ in $34.5 \%$ and $11 \mathrm{gm} / \mathrm{dl}$ or greater in $20 \%$ of pica children compared with $12 \%$ and $56 \%$ respectively in control for children. ${ }^{5}$

A study was conducted to assess the association of pica with anaemia among 63 children in the age group of 10-59 months with pica habits in a polyclinic in Tunis in Tunisia. The study used survey method comparing 63 pica children with 43 non pica children presenting a similar degree of anaemia. The study revealed that most children ingested earth, but $50 \%$ of the patients ingested multiple substances. Differences were observed between the pica children and the anaemic children without pica habits. Treatment with iron supplements led to cessation of pica in most patients. The researcher concluded that pica appears to remain very frequent among Tunisian children. The prevention requires information of parents about dietary prevention of early iron deficiency. ${ }^{6}$

A clinical trial of mentat (specially trained to mimic the cognitive and analytical ability) in children with behavioural problems was conducted at the S.N. Children's Hospital, Allahabad on 105 children whose age ranged from 2 to 5 years, suffering from various behavioural problems comprising of nocturnal enuresis, speech defects, pica, learning disability, school phobia, breath-holding spells and thumb-sucking. The result showed that marked improvement was seen in children with nocturnal enuresis, pica and breath-holding spells with mild improvement in school phobia, learning disability and speech defect. In cases of pica, apart from mentat administration the parents were given 
counselling and the cases received haematinics and nutritional additives. Improvement was seen in 8 cases, $70 \%$ showed marked improvement and 4 cases mild improvement. ${ }^{7}$

A study was conducted to establish various methods to prevent pica among 331 children from the patient sample of the child development study at the medical college of Virginia. Interview technique was used for the mothers of children below the age group of 7 years regarding pica habits of their children. The status of lead exposure was evaluated in groups of children, those with pica and those without. The result showed that children from urban areas (92\%) ingested plaster and paints more in amount compared to rural areas. In mothers of both groups of children, $64.7 \%$ believed that pica leads to lead poisoning, $26 \%$ were unaware, six (6\%) were uncertain and three ( $3 \%$ ) were ignorant. As response to the health teaching provided to the mothers of 90 children who had a heavy plaster intake, pica was stopped within a month in 46 children (51.1\%) of different age groups (under 4 years ), 35 of them (39\%) stopped within two months and 9 (10\%) of them continued the habit for more than six months. The researcher concludes that through removal of dilapidated houses, providing health education to people through leaflets, media, interviews, health clinics will help reduce pica. In addition, an aroused public as a motivating force and as a means of dealing with substandard housing and other environmental sources of lead exposure, can also be of help in reducing a preventable man made disease. ${ }^{8}$

\section{OBJECTIVES OF THE STUDY}

- To assess the demographic variables.

- To assess the pre-test and post-test knowledge scores regarding Pica habits in children among mothers of preschool children.

- To find the association of knowledge scores of mothers of pre-school children regarding pica habits in children with their selected socio demographic variables.

\section{METHODOLOGY}

For the present study, Evaluative research approach and Pre-experimental research design was used. The research setting was the rural area of Jeevan Nagar, Jammu. The sample consisted of 30 mothers of pre-school children. Non probability convenient sampling technique was used to select the sample. Prior to the data collection procedure formal permission was obtained from the mothers. Socio-demographic profile and a structured knowledge questionnaire regarding pica habits in children were used to collect the data. Data collection was done in October 2019.

Prior to the interview with the questionnaire of the subjects, the investigator gave self introduction and explained the purpose of gathering information. A good rapport was established with the subjects. They were assured that their responses would be kept confidential and the information would be used only for the purpose of research. Verbal consent was taken from the subjects. The time taken by each respondent for filling the tool was average of 15-20 minutes. After taking pre-test, the researcher gave them teaching about Pica; causes, effects and preventive measures. Then after 7 days data was again collected from them by using the same structured knowledge questionnaire and also distributing information pamphlets to the mothers of pre-school children regarding prevention of pica habits. The data gathered was analysed and calculated using percentage, mean, standard deviation and chi-square. 
RESULTS

Objective - 1: To assess the demographic variables.

Table 1

Frequency and percentage distribution of mothers of pre-school children according to socio-demographic variables

$\mathbf{N}=\mathbf{3 0}$

\begin{tabular}{|c|c|c|c|}
\hline Variables & Options & Frequency(f) & Percentage (\%) \\
\hline \multirow[t]{4}{*}{ Age (in years) } & $18-22$ & 9 & $30.0 \%$ \\
\hline & $23-27$ & 10 & $33.3 \%$ \\
\hline & $28-31$ & 5 & $16.6 \%$ \\
\hline & $32-35$ & 6 & $20.0 \%$ \\
\hline \multirow[t]{4}{*}{ Education } & Illiterate & 2 & $6.6 \%$ \\
\hline & Up to $5^{\text {th }}$ & 9 & $30.0 \%$ \\
\hline & Up to $10^{\text {th }}$ & 9 & $30.0 \%$ \\
\hline & 12th or above & 10 & $33.3 \%$ \\
\hline \multirow[t]{4}{*}{ Occupation } & Housewife & 20 & $66.6 \%$ \\
\hline & Govt. Job & 2 & $6.6 \%$ \\
\hline & Labour & 4 & $13.3 \%$ \\
\hline & Business & 4 & $13.3 \%$ \\
\hline \multirow[t]{4}{*}{ Religion } & Hindu & 3 & $10.0 \%$ \\
\hline & Sikh & 24 & $80.0 \%$ \\
\hline & Muslim & 0 & $0 \%$ \\
\hline & Christian & 3 & $10.0 \%$ \\
\hline \multirow[t]{2}{*}{ Place of residence } & Rural & 30 & $100.0 \%$ \\
\hline & Urban & 0 & $0 \%$ \\
\hline
\end{tabular}

Table - 1 reveals the frequency and percentage distribution of sample characteristics of the study subjects. Distribution of study subjects showed that maximum (33.3\%) of mothers were in the age group of 23-27 years, having education $12^{\text {th }}$ class or above, were housewives, practising sikh religion and were residing in rural areas.

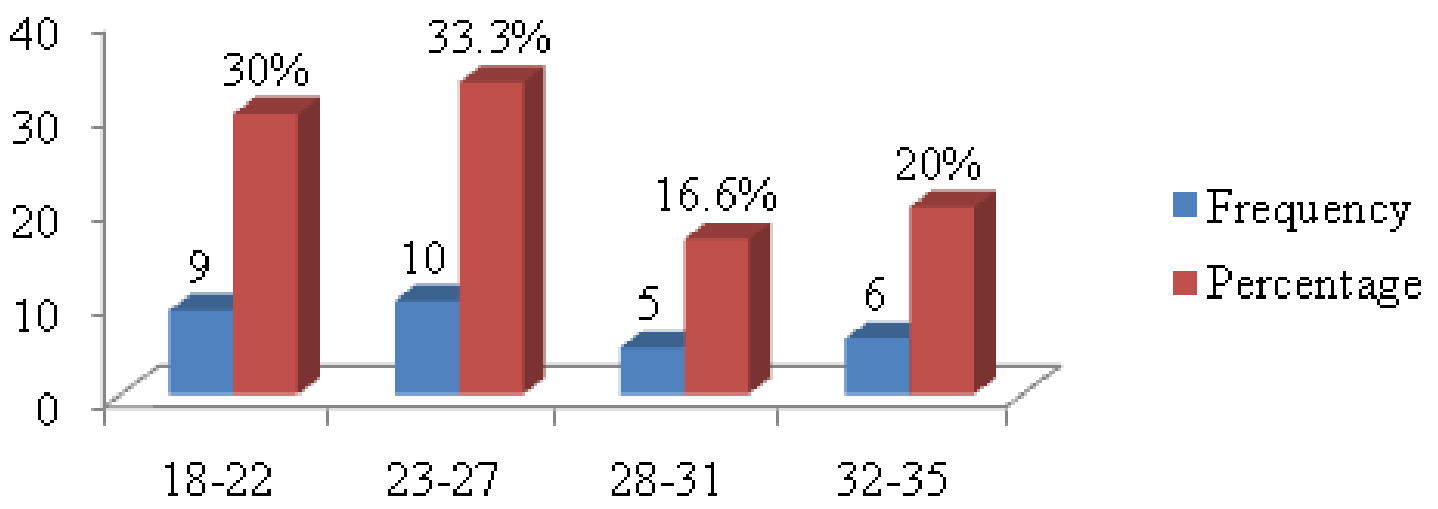

Figure 1: Frequency and percentage distribution of mothers of pre-school children according to age. 


\section{ARTICLES}

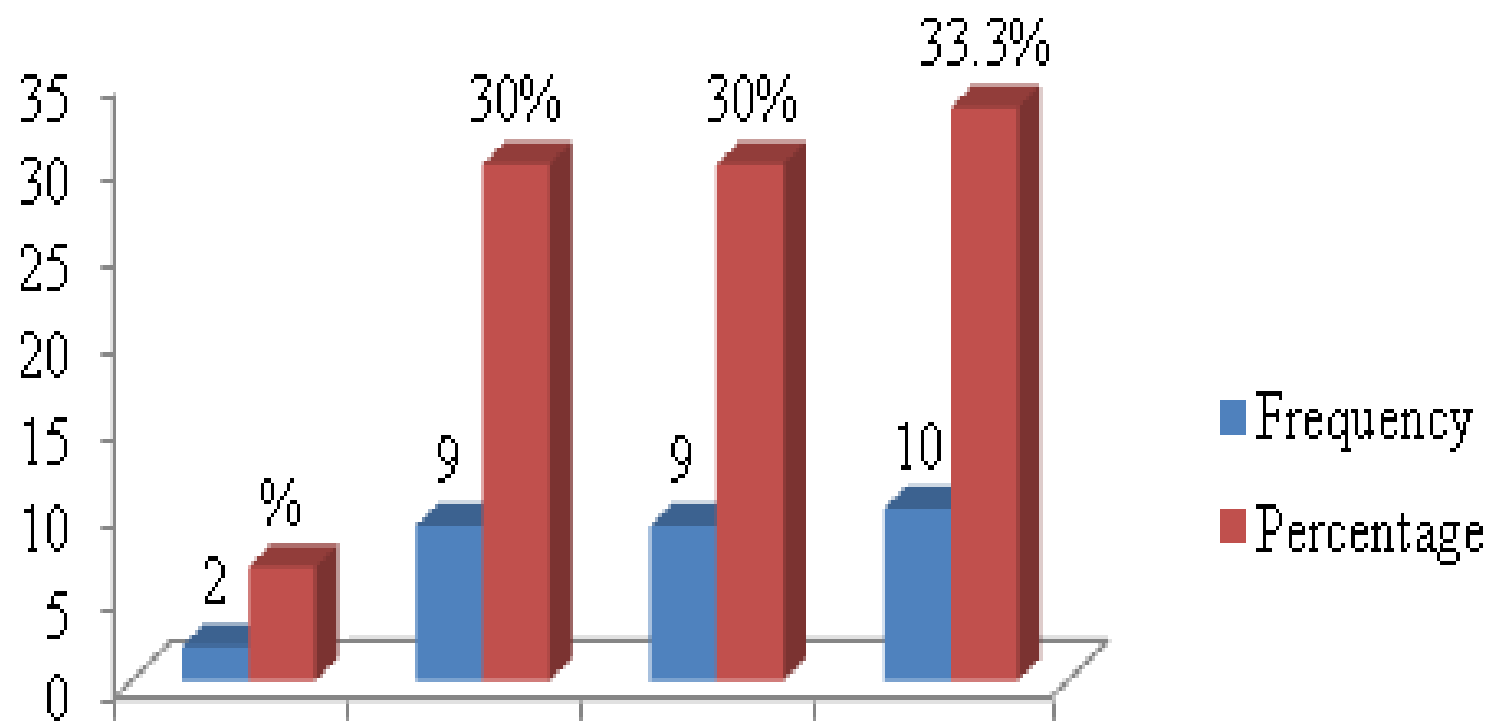

\section{Illiterate Upto 5th Upto 10 th 12 th or above}

Figure 2: Frequency and percentage distribution of mothers of pre-school children according to educational status.

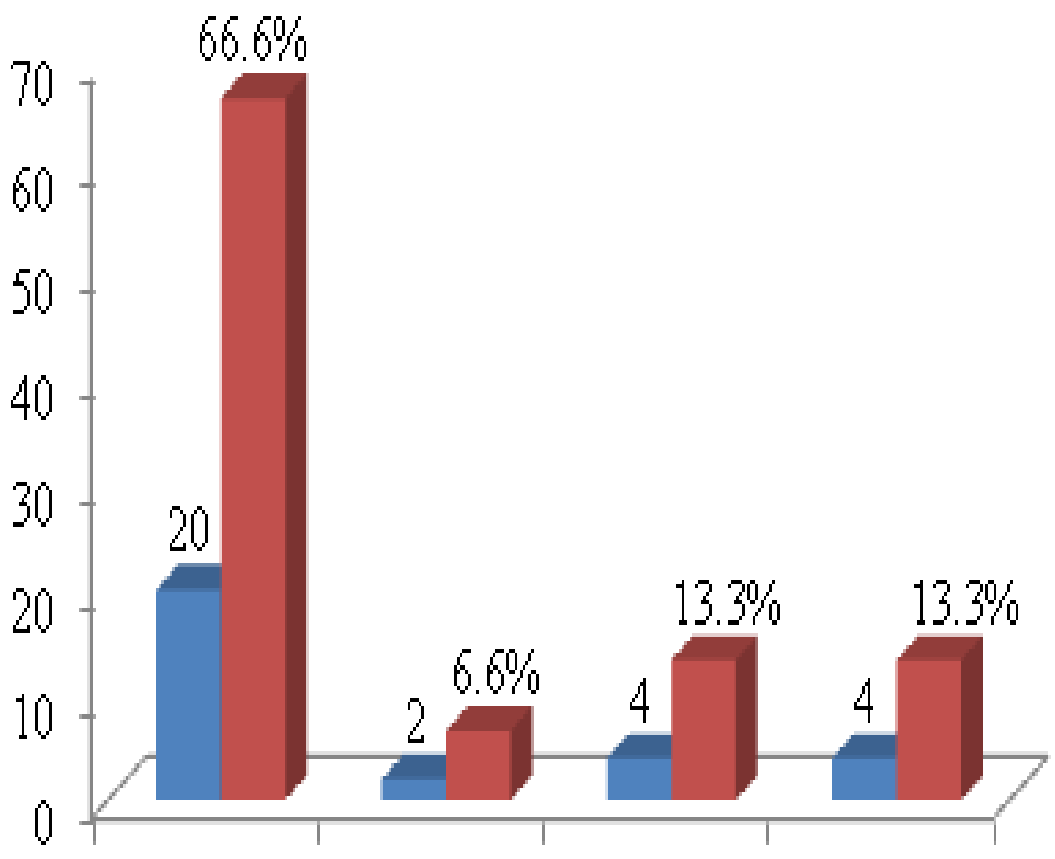

- Frequency

Percentage

\section{Housewife Gort. Job Labour Business}

Figure 3: Frequency and percentage distribution of mothers of pre-school children according to occupation. 


\section{ARTICLES}

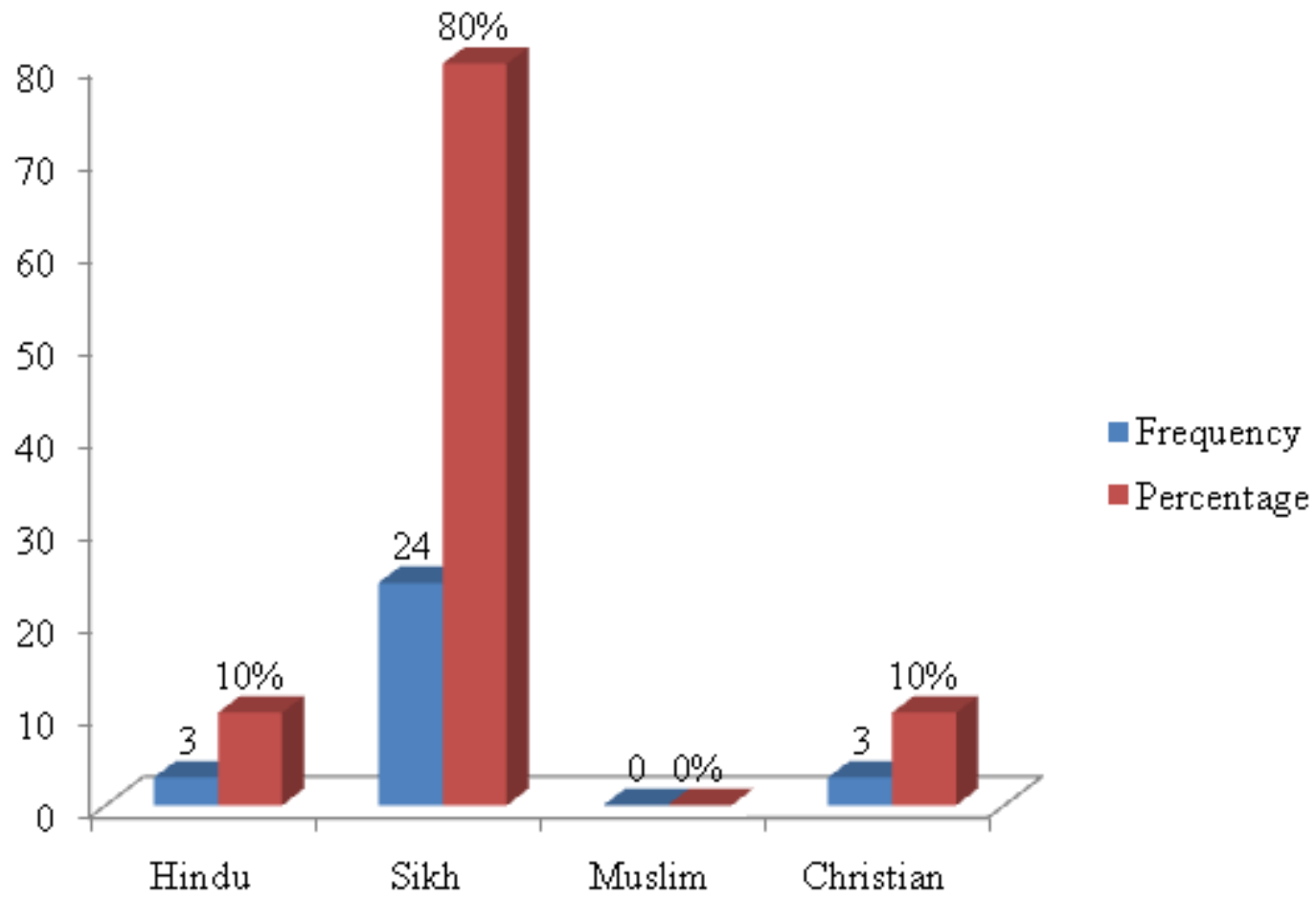

Figure 4: Frequency and percentage distribution of mothers of pre-school children according to religion.

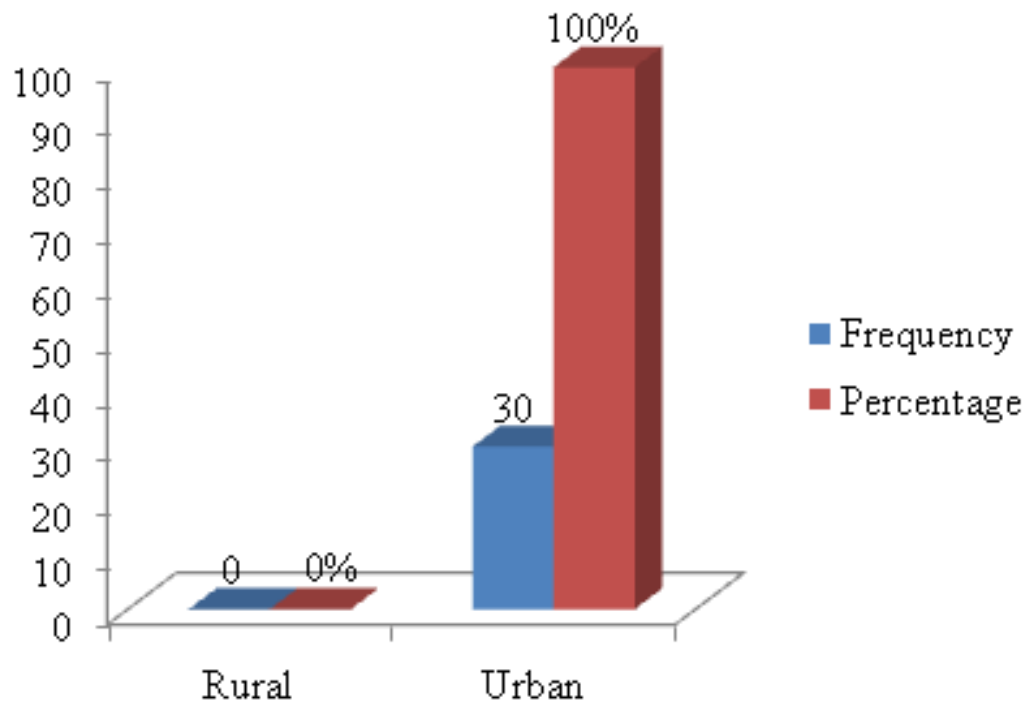

Figure 5: Frequency and percentage distribution of mothers of pre-school children according to place of residence. 
Objective - 2: To assess the pre-test and post-test knowledge scores regarding pica habits in children among mothers of pre-school children.

Table - 2

Frequency and percentage distribution of knowledge scores regarding pica habits in children among mothers of pre-school children

$\mathrm{N}=\mathbf{3 0}$

\begin{tabular}{|l|c|c|c|c|}
\hline \multirow{2}{*}{ Knowledge score } & \multicolumn{2}{|c|}{ Pre-test } & \multicolumn{2}{c|}{ Post-test } \\
\cline { 2 - 5 } & Frequency & Percentage & Frequency & Percentage \\
\hline Poor (1-5) & 3 & $10.0 \%$ & 0 & $0 \%$ \\
\hline Average (5-10) & 17 & $56.6 \%$ & 0 & $0 \%$ \\
\hline Good (10-15) & 6 & $20.0 \%$ & 0 & $100 \%$ \\
\hline Very Good (15-20) & 4 & $13.3 \%$ & 30 & $0 \%$ \\
\hline
\end{tabular}

Maximum score $=20$

Minimum score $=01$

Table - 2 reveals the pre- and post-test frequency and percentage distribution of knowledge regarding pica habits in children, among mothers of pre-school children. It shows that in pre-test maximum (56.6\%) had average knowledge followed by $20 \%$ who had good knowledge and $13.3 \%$ and $10 \%$ had very good and poor knowledge respectively; whereas post-test figures reveal that majority (100\%) of mothers had very good knowledge.

Hence, it was concluded that planned teaching programme had a great effect on the knowledge regarding pica habits of children, among mothers of pre-school children.

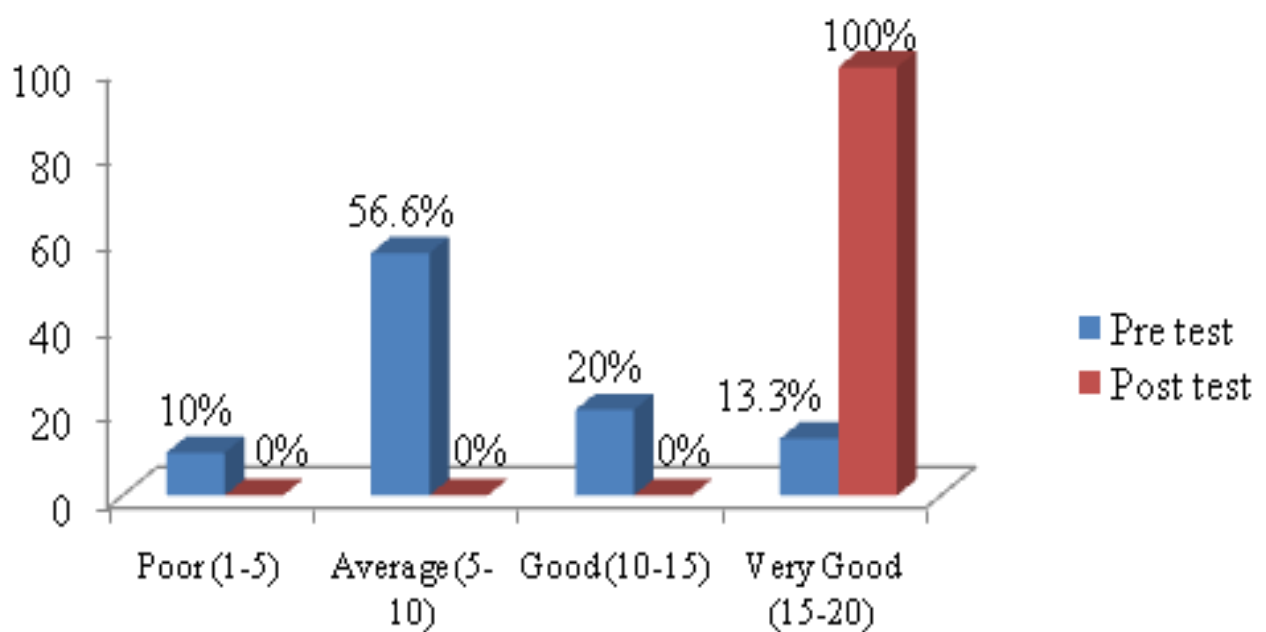

Figure 6: Percentage distribution of knowledge regarding pica habits, among mothers of pre-school children in preand post-test. 
Objective - 3: To find the association of knowledge scores of mothers of pre-school children regarding pica habits in children with their selected socio-demographic variables.

Table - 3

Association between knowledge score and selected socio-demographic variables of mothers of pre-school children

$\mathbf{N}=\mathbf{3 0}$

\begin{tabular}{|c|c|c|c|c|c|c|c|}
\hline \multirow{2}{*}{ Variables } & \multirow{2}{*}{ Options } & \multicolumn{3}{|c|}{ Knowledge score } & \multirow{2}{*}{$\begin{array}{c}\text { Chi-square } \\
\text { value }\end{array}$} & \multirow{2}{*}{$\begin{array}{l}\text { Tabulated } \\
\text { Value }\end{array}$} & \multirow{2}{*}{ df } \\
\hline & & Poor & Average & Good & & & \\
\hline \multirow{4}{*}{ Age (in yrs) } & $18-22$ & $0(0 \%)$ & $3(10 \%)$ & $6(20 \%)$ & \multirow{4}{*}{$\begin{array}{c}\chi^{2}=0.21 \\
\mathbf{s}\end{array}$} & \multirow{4}{*}{12.59} & \multirow{4}{*}{6} \\
\hline & $23-27$ & $0(0 \%)$ & $3(10 \%)$ & $7(23.3 \%)$ & & & \\
\hline & $28-31$ & $0(0 \%)$ & $1(3.3 \%)$ & $4(13.3 \%)$ & & & \\
\hline & $32-35$ & $0(0 \%)$ & $0(0 \%)$ & $6(20 \%)$ & & & \\
\hline \multirow{4}{*}{ Educational status } & Illiterate & $0(0 \%)$ & $1(3.3 \%)$ & $1(3.3 \%)$ & \multirow{4}{*}{$\begin{array}{c}\chi^{2}=7.20 \\
\mathbf{s}\end{array}$} & \multirow{4}{*}{12.59} & \multirow{4}{*}{6} \\
\hline & Up to $5^{\text {th }}$ & $0(0 \%)$ & $3(10 \%)$ & $6(20 \%)$ & & & \\
\hline & Up to $10^{\text {th }}$ & $0(0 \%)$ & $2(6.66 \%)$ & $7(23.3 \%)$ & & & \\
\hline & 12th or above & $0(0 \%)$ & $1(3.33 \%)$ & $9(30 \%)$ & & & \\
\hline \multirow{4}{*}{ Occupation } & Housewife & $0(0 \%)$ & $5(16.6 \%)$ & $15(50 \%)$ & \multirow{4}{*}{$\begin{array}{c}\chi^{2}=6.46 \\
\mathbf{s}\end{array}$} & \multirow{4}{*}{12.59} & \multirow{4}{*}{6} \\
\hline & Govt. Job & $0(0 \%)$ & $0(0 \%)$ & $2(6.66 \%)$ & & & \\
\hline & Labour & $0(0 \%)$ & $2(6.66 \%)$ & $2(6.66 \%)$ & & & \\
\hline & Business & $0(0 \%)$ & $0(0 \%)$ & $4(13.3 \%)$ & & & \\
\hline \multirow{4}{*}{ Religion } & Hindu & $0(0 \%)$ & $1(3.3 \%)$ & $2(6.66 \%)$ & \multirow{4}{*}{$\begin{array}{c}\chi^{2}=0.03 \\
\mathbf{s}\end{array}$} & \multirow{4}{*}{12.59} & \multirow{4}{*}{6} \\
\hline & Sikh & $0(0 \%)$ & $5(16.6 \%)$ & $19(63.3 \%)$ & & & \\
\hline & Muslim & $0(0 \%)$ & $0(0 \%)$ & $0(0 \%)$ & & & \\
\hline & Christian & $0(0 \%)$ & $1(3.3 \%)$ & $2(6.6 \%)$ & & & \\
\hline \multirow{2}{*}{ Residence } & Rural & $0(0 \%)$ & $0(0 \%)$ & $0(0 \%)$ & \multirow{2}{*}{$\begin{array}{c}\chi^{2}=0 \\
s\end{array}$} & \multirow{2}{*}{12.59} & \multirow{2}{*}{2} \\
\hline & Urban & $0(0 \%)$ & $7(23.3 \%)$ & $23(76.6 \%)$ & & & \\
\hline
\end{tabular}

Table - 3 shows the association of knowledge score of mothers regarding pica habits with selected socio-demographic variables, chi-square test result depicts that there was significant association of knowledge score of mothers of preschool children with selected socio-demographic variables at 0.05 level of significance.

\section{DISCUSSION}

Objective - 1: To assess the demographic variables

Distribution of study subjects showed that maximum (33.3\%) of mothers were in the age group of 23-27 years, had education of $12^{\text {th }}$ class or above, were housewives, practising sikh religion and were residing in rural areas. These findings are supported by a study to assess the knowledge regarding behavioural problems of pre-school children among parents in a selected urban and rural area. ${ }^{9}$

Objective - 2: To assess the pre-test and post-test knowledge scores regarding pica habits in children among mothers of pre-school children.

Knowledge regarding pica habits in children among mothers of pre-school children shows that in pre-test, maximum $(56.6 \%)$ had average knowledge followed by $20 \%$ having good knowledge and $13.3 \%$ and $10 \%$ had very good and poor knowledge, respectively; whereas post-test figures reveal that majority (100\%) of mothers had very good knowledge. This is inconsistent with a comparative study conducted to assess the knowledge regarding behavioural problems of pre-school children among parents in a selected rural and urban area since it revealed that maximum 41 (68.33\%) of the subjects from rural areas had average knowledge followed by 10 (16.67\%) having good knowledge and only 9 (15.00\%) had poor knowledge regarding behavioural problems of preschool children. ${ }^{10}$ 
Objective - 3: To find the association of knowledge scores of mothers of pre-school children regarding pica habits in children, with their selected socio-demographic variables.

In respect of finding association of knowledge scores of mothers of pre-school children regarding pica habits in children with their selected socio-demographic variables, the chi-square test result depicts that there was significant association of knowledge score of mothers of pre-school children with their selected socio-demographic variables at 0.05 level of significance. This is consistent with a study conducted to assess the behavioural problems in young children in rural Bangladesh, as it also concluded that behaviour impairments were significantly associated with socio-demographic variables. ${ }^{11}$

\section{CONCLUSION}

The present study concluded that the planned teaching programme had a great effect on the knowledge regarding Pica habits in children, among mothers of pre-school children. The major goal of imparting knowledge is to bring about changes in the behavioural habits.

\section{REFERENCES}

1. Wong's. Essentials of pediatric nursing. $8^{\text {th }}$ Edition. Mosby publications $P, 2-3$.

2. Dr. Kristie. Pica- A very strange eating disorder.

Available from: http://www.rusticgirls.com/health /pica-eating-disorder-3.html

3. Bruce.E. Johnson. Pica. Chapter-148.

Available from: http://www.ncbi.nlm. nih.gov.books/NBK255/\#A4441

4. Dr Joginder S G, S.P.S Yadav. (2008). Complications of pica. Case report and review of literature. The international journal of head and neck surgery; 2(2).

Available from: http://www.ispub.com/journal/the-internet-journal-of-head-and-neck-surgery/volume-2-

number-2/complications-of-pica-case-report-and-review-of-literature.html

5. Gupta R K, Gupta R. (2005). Clinical profile of pica in childhood. JK Science. 7(2):61-3.

6. Karoui A, Karoui H. Pica in Tunisian children. Results of a survey performed in a polyclinic of the Tunisian social security national administration. France. Available from:

http://www.ncbi.nlm.nih.gov/pubmed?term=pica\%2Bchildren

7. Sharan R, Khare R. A clinical trial of mentat in children with behavioral problems.

Available from: www.himalayahealthcare.com

8. Brigitte de la Burd and Reames B, ACSW. Prevention of Pica, The Major Cause of Lead Poisoning in Children. Ajph. 63 (8).

Available from : ajph.aphapublications.org/cgi/reprint/63/8/737.pdf

9. Manivannan D et al. (2017). A Study To Assess The Knowledge Regarding Behavioral Problems Of School Children Among Mothers. 6(6), PP 13-16.

10. Sangole S. (2019). A Comparative Study to Assess the Knowledge regarding Behavioral Problems of Preschool Children among Parents in Selected Urban and Rural Area. International Journal of Science and Research (IJSR). $8(4)$.

11. Khan N et al. (2009).Behaviour Problems in Young Children in Rural Bangladesh . Journal of Tropical Pediatrics, 55(3), 177-182. https://doi.org/10.1093/tropej/fmn108 